\title{
Hydrogen Bonding in High-Z' Molecular Structures
}

Veronica Carta, ${ }^{a}$ Huachen Lin, ${ }^{a}$ Maren Pink ${ }^{a}$ and Thomas N. Snaddon ${ }^{a}$

a Department of Chemistry, 800 E Kirkwood Ave, Indiana University, Bloomington, IN, 47405, USA. vcarta@iu.edu

Strong intermolecular interactions, such as hydrogen bonding, often occur in crystal structures with Z'>1, and they contribute to the formation of structural layers. In this poster we discuss the structure solution and refinement of an enantiomerically pure organic molecule that crystalizes in the rare space group P1. Four separate molecules are present in the asymmetric unit $\left(\mathrm{Z}^{\prime}=4\right)$ and long parallel $\mathrm{H}$-bonded chains contribute to the formation of a layered structure. 